\title{
X-ray Fluorescence Analysis of Obsidian Artifacts from Cheshmeh Ali, Iran
}

\author{
by \\ Michael D. Glascock (University of Missouri) \\ glascockm@missouri.edu \\ Ahmad Chaychi Amirkhiz \\ (Iranian Center of Archaeological research) chaychi1392@gmail.com
}

\begin{abstract}
Rare Prehistoric obsidian Artifacts have been found in Central Plateau of Iran . late Neolithic and Chalcolithic Societies in this region had progressive industry and glory independent culture is known as Cheshme Ali culture -fine red pottery culture - which spread out North East of Iran and Turkmenistan. Obsidian provenance study of this culture is very important to determine trade routes and interactive relations with Anatolia and Mesopotemia as cradle of civilization. The famous Cheshme Ali site near Tehran has been excavated by Erich Schmidt 1934-1936 and findings have been kept by University of Pennsylvania Museum.

Nine lithic artifacts from this site were submitted to Archaeometry Laboratory of the University of Missouri Research Reactor (MURR) for analysis by non-destructive X-ray fluorescence (XRF). Eight of the Cheshmeh Ali artifacts were obsidian and were discovered to be from sources located in Turkey and Armenia. The ninth artifact was found not to be an obsidian, but instead was made from chert.
\end{abstract}

Key words : XRF , Obsidian , Cheshmeh Ali , Central Plateau of Iran 


\section{Introduction}

Due to its ability to produce a sharp edge and its attractive color, obsidian has been used by many cultures around the world wherever the volcanic glass was readily available.

Obsidian utilization in the ancient Near East began during the early Neolithic and continued through the Bronze Age (Renfrew et al. 1966).

The quantity and size of obsidian tools which find in an archaeological research depends on trade route and measure of distance to mine. By the way there are another parameters like Human interest, climate changing and geomorphology of region.

Comparing these items in Neolithic and Chalcolithic sites in Zagros and beyond ( Iran , Iraq and turkey)with each other could reveal us the pattern of obsidian distribution and finally make hypothesis for provenance studies. Jarmo obsidians study in Iraqi Zagros is an example Hole (1983).

Renfrew \& Bann (2001) suggested that the Dehluran obsidian artifacts in southwest of Iran near Iraq boarder originated from east turkey mines so there was a long distance trade about 7500 B.C which passed away from Mesopotemia. This trade was continued till $6^{\text {th }}$ millennium B.C. and Renfrew based on provenance studies(Blacman,1984) thinks this route has been changed after 5000 B.C towards Urmia Lake route. Provenance studies of chalcolithic obsidian artifacts from east of urmia lake made hypothesis that the route of obsidian at this period probably passed from south of urmia lake and linked Van sources to interior of Iranian archeological sites in Central Plateau .(Niknami,et al.2010).

A contrasting view exists (Rafifar1991), similarities between Alikosh(Dehluran)obsidians and obsidians from the Banan Mountains of Kerman province and eastern Afghanistan indicate possibility of alternative trade routes may have existed.

However, The highest concentrations of obsidian sources in the Near East are located in eastern Turkey and the Caucasus region countries (i.e., Armenia, Azerbaijan, and Georgia).

Geochemical studies of obsidian from sources in the Near East have been conducted by Blackman (1998), Keller et al. (1994) and numerous others using a variety of analytical techniques including neutron activation analysis (NAA), X-ray fluorescence (XRF), particle induced X-ray emission (PIXE), and inductively coupled plasma-mass spectrometry (ICP-MS). As 
a consequence, the locations of obsidian sources in the region are reasonably well known. And, the methods for assigning obsidian artifacts to sources are also well established (Glascock et al. 1998).

The Archaeometry Laboratory at MURR recently obtained source samples from many of the obsidian sources in Turkey and Armenia for chemical characterization. Colleagues from other laboratories provided the MURR laboratory source samples in exchange for a commitment to share the data collected. The samples were analyzed comprehensively by both NAA and XRF methods. The database for Near Eastern obsidian sources currently covers more than half of the known sources in the region. The source data were used in this study.

\section{Cheshmeh Ali}

Cheshmeh Ali is a small Late Chalcolithic mound located within the southern foothills of the Elburz Mountains of Iran separating the interior deserts from the subtropical area that surrounds the Caspian Sea to the north. The prehistoric mound is located next to a small spring. The geography of the region was very important in terms of transportation. The site of Cheshmeh Ali is located along the Silk Road trade route which followed for a time the southern flanks of the Elburz Mountains. Movement of people, goods, and ideas along sections of the trade route took place as far back as 7,000 years ago when Cheshmeh Ali was likely to have been a flourishing village. The city of Ray, dating primarily to the Islamic period (A.D. 637-1220), surrounds and covers most early site deposits, including the mound of Cheshmeh Ali. Today, with exception of the high mound which has been preserved as a city park, a majority of Cheshmeh Ali has been destroyed by the urban expansion of Tehran.

The archaeological site of Cheshmeh Ali was excavated by Erich Schmidt from 19341936 as part of a joint project between the University Museum of the University of Pennsylvania and the Boston Museum of Fine Arts (Schmidt 1935). This work established that Cheshmeh Ali was one of the most important sites in the northern Iran during the Neolithic/Chalcolithic sequence due to the excellent preservation of architecture and the rich assemblage of artifacts found by Schmidt and his crew of excavators. Unfortunately, Schmidt was killed in a plane crash in 1964 and the results of his excavations at Cheshmeh Ali have yet 
to be fully reported. Between 1997 and 2001 Hassan Fazeli conducted new excavations included surface expeditions in Cheshme ali and Zaghe on the Qazvin plain. These research expanded with multidisciplinary studies as radiocarbon dating and pottery XRF analysis. The fine cheshmeh Ali pottery(Sialk I\& II) culture has been dated to 5200-4300 B.C and belonged to technological changes in ceramic production between The Late Neolithic and The Transitional Chalcolithic period.(Wong, et al.2010)

The artifacts uncovered by Schmidt included extensive collections of painted pottery and a small number of lithic samples now archived at the University of Pennsylvania Museum of Archaeology and Anthropology and the Oriental Institute of the University of Chicago. The lithic samples in this study were made available by the University of Pennsylvania.

\section{Methodology}

An Elva-X energy dispersive X-ray fluorescence (ED-XRF) spectrometer was employed to perform this study. The spectrometer is equipped with an air-cooled rhodium target anode Xray tube with 140 micron Be window and a thermoelectrically cooled Si-PIN diode detector. The detector has a resolution of $180 \mathrm{eV}$ for the $5.9 \mathrm{keV}$ from iron. The beam dimensions are $3 \mathrm{x}$ $4 \mathrm{~mm}$. In order to measure the elements in this study (K, Ti, Mn, Fe, $\mathrm{Zn}, \mathrm{Ga}, \mathrm{Rb}, \mathrm{Sr}, \mathrm{Y}, \mathrm{Zr}$, and $\mathrm{Nb})$, the X-ray tube was operated at $40 \mathrm{kV}$. Count rate stabilization was used to adjust the current such that the count rate was approximately 6,000 counts per second on each sample. For most artifacts the current ranged from 20-25 microamps. Measurement times were 300 seconds per sample. Peak deconvolution and element concentrations were accomplished using the ElvaX spectral analysis package. The instrument was calibrated using data collected by XRF and NAA a series of well-characterized obsidian source samples in the MURR reference collection from Mexico, Guatemala, Peru and the Western US. Artifacts with a flat surface greater than $0.8 \mathrm{~cm}$ across are best, but samples as small as $0.5 \mathrm{~cm}$ across are able to be sourced in most cases. Very small samples should be submitted to neutron activation analysis (NAA).

The trace element concentration values measured from the artifacts were compared to data for known obsidian sources reported in the literature and unpublished element data in the 
Archaeometry Laboratory measured previously on source samples obtained from Armenia, Azerbaijan, Georgia and Turkey. Source determinations were performed with the assistance of bivariate plots of the data for artifacts compared with confidence ellipses for the obsidian sources. Artifacts were assigned to a specific source if the diagnostic trace element values fell within two standard deviations of the analytical uncertainty of the upper and lower limits of chemical variability recorded for the source. As many elements as possible are used in these comparisons to make the results more reliable.

\section{Results}

The XRF results for the Cheshmeh Ali artifacts in this study are presented in Table 1. One of the samples (RCh7099) as found to have extremely low concentrations for almost all elements indicating that it is not made from obsidian but is instead made from chert. Using the data for $\mathrm{Rb}$ and $\mathrm{Sr}$ from the remaining artifacts a bivariate plot shown in Figure 2 compares the with $95 \%$ confidence ellipses for the major obsidian sources. Six of the obsidian artifacts were found to be from the important source at Nemrut Dag, Turkey. The remaining pair of artifacts came from the Gutansar and Mets Arteni sources in Armenia. A summary of the source assignments is given in Table 2 .

\section{Conclusions}

Obsidian was not locally available to the people of Cheshmeh Ali. despite of eastern possible route, It seems that; The nearest sources were located about $1000 \mathrm{~km}$ distance in Eastern Anatolia and Armenia. However, because the village was an important waypoint along the ancient Silk Road, it is highly probable that in exchange for food and lodging passing traders would offer the people of Cheshmeh Ali obsidian from those sources in Eastern Anatolia and Armenia which were also along the Prehistoric long distance trading route like Silk road. The Nemrut Dag source was apparently the most popular source as $75 \%$ of the obsidian artifacts analyzed in this study came from this source. The remaining artifacts came from the Armenian sources at Gutansar and Mets Arteni. 


\section{Bibliography}

Blackman J.M.

1984 Provenance Studies of Middle Eastern Obsidian from Sites in Highland Iran, in Archaeological Chemistry - III,pp 19-50, series.205 ,American Chemical Society, Washington

Blackman, J. M., R. Badalian, Z, Kikodze and Ph. Kohl

1998 Chemical characterization of Caucasian obsidian geological sources. In L'obsidienne au Proche et Moyen Orient, edited by Cauvin, M.C.; A. Gourgaud, B. Gratuze, N. Arnaud, G. Poupeau, J.L. Poidevin and C. Chataigner, pp. 205-231. BAR Inter Series 738.

Glascock, M.D., G.E. Braswell and R.H. Cobean

1998 A systematic approach to obsidian source characterization. In Archaeological Obsidian Studies: Method and Theory, edited by M.S. Shackley, pp. 15-65. Plenum Press: New York and London.

Hole, F.

1983 additional remarks on the Jarmo obsidian in Prehistoric Archaeology along the Zagros Flanks edited by Braidwood et al ,pp.285-7, the Oriental Institute of the University of Chicago.

Keller, J., R. Djerbasian, S.G. Karapetian, E. Pernicka and V. Nasedkin

1994 Armenian and Caucasian obsidian occurrences as sources for the Neolithic trade: volcanological setting and chemical charateristics. In Archaeometry 94, The Proceedings of the 29th Symposium on Archaeometry, Ankara 9-14 May 1994, edited by Demirci, S.; Ozer, A.M.; Summers, G.D., pp. 69-85. Tubitak: Ankara.

Niknami, K. A.C. Amirkhiz, M.D.Glascock

2010 Provenance Studies of Chalcolithic Obsidian Artefacts from near Lake Urmia, Northwestern Iran usig WDXRF Analysis,Archaeometry 52,pp.19-30

Rafifar, J.

1991 Obsidian distributions in Iran and its role in the oldest culture and technological exchanges,Journal of Archaeology and History ,5,pp.14-25(in Persian)

Renfrew, C., J.E. Dixon and J.R. Cann 
1966 Obsidian and early cultural contact in the Near East. Proceedings of the Prehistoric Society, 32: 30-72.

Renfrew, C. P.Bann

2001 Archaeology : Theories, Methods and Practice $3^{\text {rd }}$ edition ,Hudson

Schmidt, Erich

1935 The Persian expedition. University Museum Bulletin 5(5): 41-49.

Wong Edna, H. Cameron A. Petrie and Hassan Fazeli

2010 Cheshmeh Ali Ware ; A Petrographic and Geochemical Study of A Transitional Chacolithic Periox Ceramic Industry on The Northern Central Plateau of Iran. 
Table 1. Concentrations of elements in artifacts from Cheshmeh Ali measured by X-ray fluorescence.

\begin{tabular}{lrrrrrrrrrrr}
\hline ANID & $\mathbf{K}(\%)$ & \multicolumn{1}{c}{ Ti } & Mn & Fe(\%) & \multicolumn{1}{l}{ Zn } & \multicolumn{1}{l}{ Ga } & Rb & \multicolumn{1}{l}{ Sr } & \multicolumn{1}{c}{ Y } & \multicolumn{1}{c}{ Zr } & Nb \\
\hline RCh1401 & 3.19 & 703 & 278 & 2.131 & 217 & 21 & 207 & 0 & 147 & 1237 & 70 \\
RCh1426 & 3.47 & 768 & 312 & 2.154 & 224 & 21 & 220 & 0 & 151 & 1235 & 71 \\
RCh1457 & 3.93 & 728 & 311 & 2.017 & 214 & 24 & 220 & 0 & 132 & 1166 & 64 \\
RCh1533 & 3.23 & 1836 & 438 & 0.765 & 48 & 15 & 142 & 167 & 13 & 188 & 34 \\
RCh1540 & 3.48 & 753 & 265 & 1.806 & 181 & 21 & 198 & 0 & 131 & 1147 & 63 \\
RCh1544 & 3.27 & 841 & 288 & 2.267 & 237 & 22 & 206 & 0 & 162 & 1294 & 76 \\
RCh1548 & 3.88 & 749 & 347 & 0.554 & 40 & 15 & 143 & 30 & 17 & 94 & 29 \\
RCh1563 & 3.28 & 676 & 302 & 0.231 & 229 & 22 & 216 & 0 & 157 & 1259 & 74 \\
RCh7099 & 2.01 & 25 & 57 & 0.113 & 32 & 0 & 15 & 21 & 0 & 4 & 0 \\
\hline
\end{tabular}

All concentrations are given in parts per million unless otherwise indicated.

Table 2. Source assignments for artifacts from Cheshmeh Ali.

\begin{tabular}{ll}
\hline ANID & Source name \\
\hline RCh1401 & Nemrut Dag, Turkey \\
RCh1426 & Nemrut Dag, Turkey \\
RCh1457 & Nemrut Dag, Turkey \\
RCh1533 & Gutansar, Armenia \\
RCh1540 & Nemrut Dag, Turkey \\
RCh1544 & Nemrut Dag, Turkey \\
RCh1548 & Mets Arteni, Armenia \\
RCh1563 & Nemrut Dag, Turkey \\
RCh7099 & chert not obsidian \\
\hline
\end{tabular}




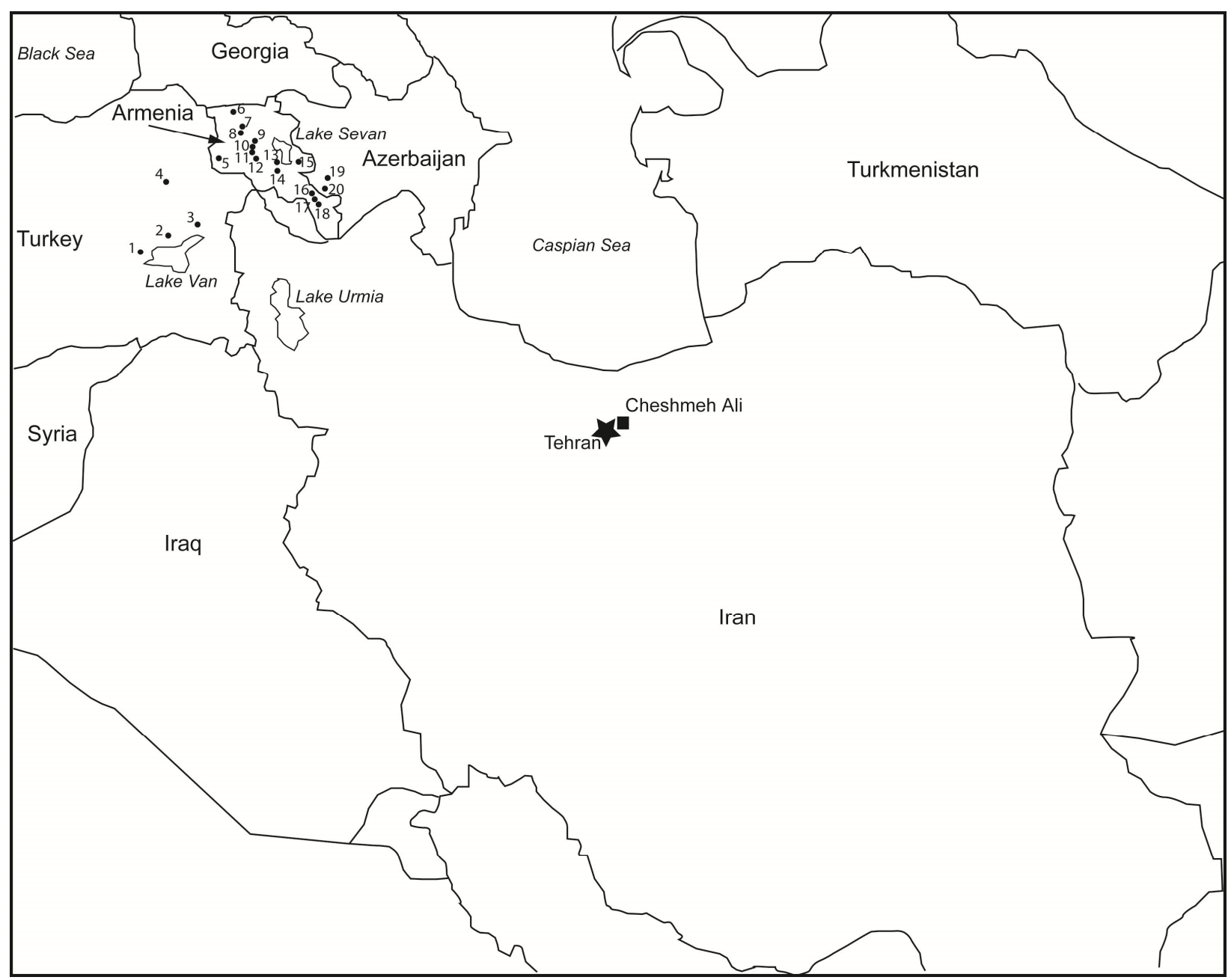

Figure 1. Map showing the locations of obsidian sources in Eastern obsidian sources in Iran and the Caucaus region Blackman et al. (1998) and Keller et al. (1996) are labeled: 1=Nemrut (four compositional types), 2=Suphan, 3=Maydan, 4=Sarikamis, 5=Arteni (three compositional types), 6=Ashotsk (two compositional types), 7=Hankavan, 8=Kamakar, 9= Alaphars, 10=Fontan, 11=Gutansar, 12=Hatis, 13=Spitaksar, 14=Geghasar, 15= Choraphor, 16=Satanakar (three compositional types), 17=Sevkar, 18=Bazenk, 19=Kelbedzhar, and 20=Ketchal. 


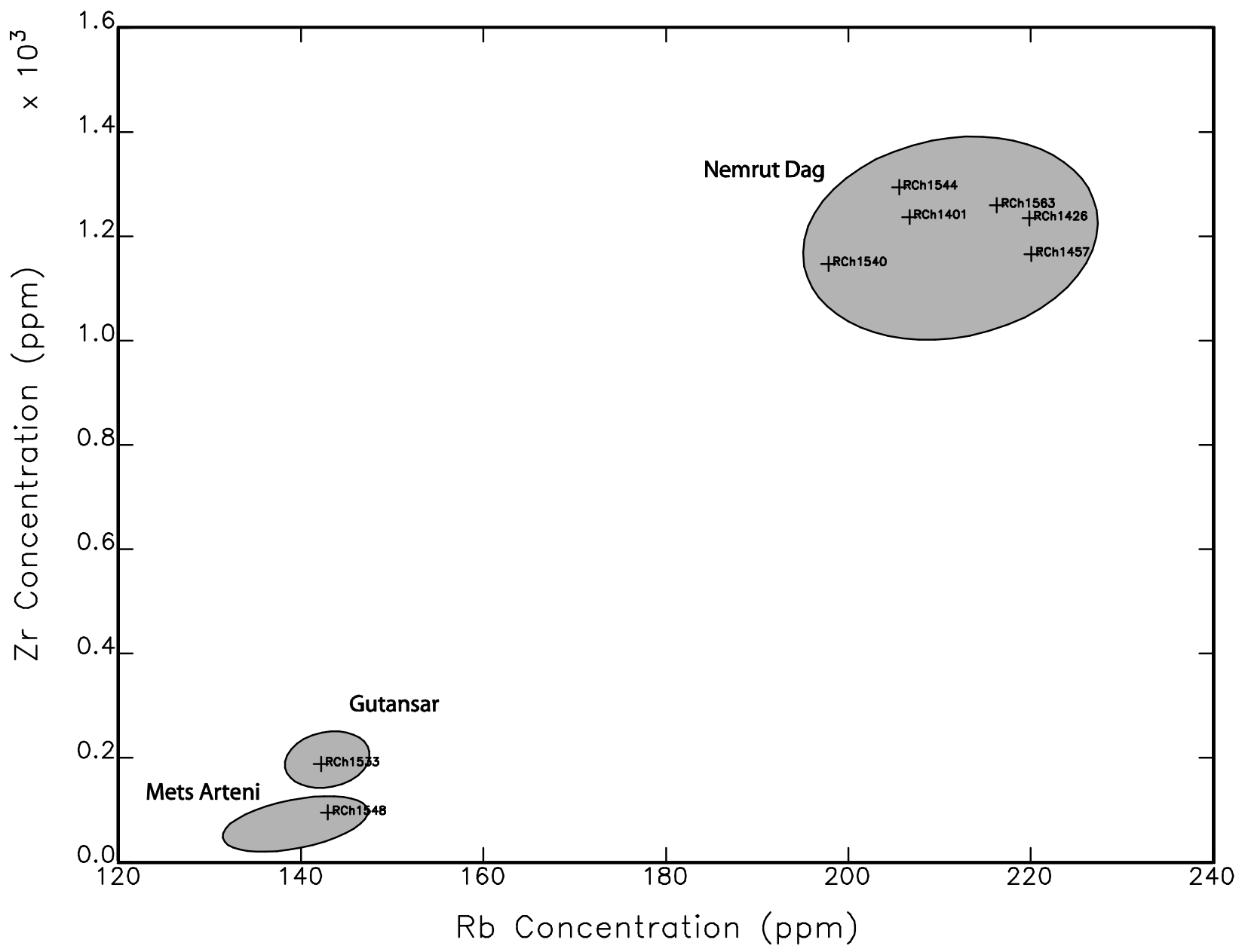

Figure 2. Bivariate plot of $\mathrm{Rb}$ versus $\mathrm{Zr}$ for obsidian artifacts from Cheshmeh Ali compared to sources from Armenia and Turkey identified in this study. Ellipses are shown at the $95 \%$ confidence level. 